recommendations of the independent enquiry into modernising medical careers. London: Aldridge Press, 2008. http://www.mmcinquiry.org.uk/Final_8_Jan_08 _MMC_all.pdf (accessed 11 Jan 2011).

10. Medical Specialty Training. The Gold Guide (4th edn). A reference guide for postgraduate specialty training in the UK. June 2010. http://www.mmc.nhs.uk/pdf/Gold\% 20Guide\%202010\%20Fourth\%20Edition\%20v08.pdf (accessed 11 Jan 2011)

11. MedSIN. Core global health content. Bristol: MedSIN, 2010. http://www.medsin.org/coreglobalhealth (accessed 11 Jan 2011).

12. Admin. Alma Mata: global health network. London: Alma Mata Global Health Network, 2005.

http://www.almamata.net/

news/content/alma-mata-global-health-network (accessed 11 Jan 2011).

13. WHO. Primary health care; now more than ever. London: World Health Organisation, 2008 http://www.who.int/whr/ 2008/08_overview_en.pdf (accessed 11 Jan 2011).

14. WHO. Declaration of Alma-Ata. International conference on primary health care, Alma-Ata, USSR, 6-12 September 1978. London: World Health Organisation, 1978. http://www.who.int/hpr/NPH/docs/ declaration_almaata.pdf (accessed 11 Jan 2011).

DOI: 10.3399/bjgp11X556326

\section{Experiences of academic GP specialty trainees}

We were very interested to read the article by Rees and Stephenson on the future of medical education in the UK. ${ }^{1}$ We are two academic GP specialty trainee 4s (ST4) who are enthusiastic about raising the profile of research and education in primary care. Academic ST4 training consists of a year attached to an academic department, and time is split equally between clinical practice and academic work. We also meet monthly for a training half day with the other GP ST4 trainees. This post is giving us the opportunity to refine our clinical general practice while developing further skills in teaching and research.

We are currently teaching third year medical students about the particular challenges of general practice consulting through using small group role play, and have also been involved in formative objective structured clinical examination assessments. In addition, we have completed an introductory course on teaching in primary care. We are finding this experience enjoyable and rewarding.
The guidance of experienced educationalists has given us confidence in negotiating the transition from learner to teacher.

Our research activities are based around ongoing trials in which we are learning to analyse data and present our findings at the Society for Academic Primary Care. We will also be involved in updating a systematic review and organising a pilot study with supervision from GP researchers in the department.

A supported introduction to research is an ideal way to make this area more accessible to GP trainees.

Working in an academic department at an early stage in our training is a unique opportunity to forge long-lasting links with educators and researchers. We hope we can carry this experience forward into our future careers. Inspiring academic interest among young GPs through dedicated foundation year 2 and ST4 positions is crucial to raising the profile of teaching and research within primary care. The Walport report ${ }^{2}$ emphasises the importance of integrated academic training. There are currently only 10 academic GP ST4 posts available in London. We very much hope that in the future there will be wider opportunity for GP trainees to participate in academia and benefit from similar career-enriching experiences.

\section{Rachel Conroy,}

Academic GP ST4 Trainee, St George's

Medical School, University of London.

E-mail: rconroy@sgul.ac.uk

\section{Elora Baishnab,}

Academic GP ST4 Trainee, St George's Medical School, University of London.

\section{REFERENCES}

1. Rees JP, Stephenson AE. The future of medical education in the UK. Br J Gen Pract 2010; 60(580): 759-796.

2. UK Clinical Research Collaboration and Modernising Medical Careers. Medically- and dentally-qualified academic staff: recommendations for training the researchers and educators of the future. London: Modernising Medical Careers, 2005.

http://www.nihrtcc.nhs.uk/intetacatrain/index_html/co py_of_Medically_and_Dentally-qualified Academic_Staff_Report.pdf (accessed 11 Jan 2011).

DOI: 10.3399/bjgp11X556335

\section{Chronic daily headache}

Simpson et al's splendid evaluation of direct access concluded that direct access computerised tomography (CT) is now the preferred choice for patients with chronic daily headache in primary care. ${ }^{1}$ They decided this after a rigorous identification of abnormal findings in the study, plus an economic analysis comparing CT scanning with other investigative options. We believe there is a third option - of no investigation and no referral.

The first reason for our view is given in the paper itself. Sixty scans (1.4\%) from 4404 yielded a probable cause of the headache. A further 401 (9.1\%) had incidental abnormalities. Of the 60 with abnormalities likely to be causative of the headache, four meningiomas, two metastases, two pituitary tumours, and two colloid cysts were resected: four other lesions led to surgery. We do not know if any of these patients had their symptoms improved, or even if the abnormalities actually were the cause of the symptoms. Their Table $3^{1}$ shows a higher rate of imaging abnormalities in an asymptomatic population than in the headache population (albeit using magnetic resonance imaging, that is more sensitive) making it very likely that some of the abnormalities were not relevant.

What the authors omit from their deliberations is the clinical cost of CT scanning. One in 8100 women aged 40 will develop cancer from a single CT brain scan, with some forms of CT scanning posing a one in 80 risk of causing a cancer. ${ }^{2-3}$ These figures surely tip the balance. We know that many patients suffering chronic headache request CT scanning for reassurance. ${ }^{4}$ We also know a negative scan does reduce requests for medical care. ${ }^{5}$ However, the 'cost' may be too high. We GPs need to be honest in advising the patient that over 300 scans will have to be done for one patient to have a treatable abnormality - with no guarantee of therapeutic success - and that $27(9 \%$ of 300$)$ incidental abnormalities will be found in these 300 